\title{
Temperature, air pollution, and mortality from myocardial infarction in São Paulo, Brazil
}

R. Sharovsky,

L.A.M. César and

J.A.F. Ramires
Unidade Clínica de Coronariopatia Crônica, Instituto do Coração (InCor), Faculdade de Medicina, Universidade de São Paulo, São Paulo, SP, Brasil
Correspondence

L.A.M. César

Departamento de Doenças Coronárias InCor, FM, USP

Av. Enéas de Carvalho Aguiar, 44 05403-009 São Paulo, SP

Brasil

E-mail: dcllucesar@incor.usp.br and

lucesar@uol.com.br

Publication supported by FAPESP.

....................

Received October 22, 2003

Accepted August 5, 2004

..................

\section{Abstract}

An increase in daily mortality from myocardial infarction has been observed in association with meteorological factors and air pollution in several cities in the world, mainly in the northern hemisphere. The objective of the present study was to analyze the independent effects of environmental variables on daily counts of death from myocardial infarction in a subtropical region in South America. We used the robust Poisson regression to investigate associations between weather (temperature, humidity and barometric pressure), air pollution (sulfur dioxide, carbon monoxide, and inhalable particulate), and the daily death counts attributed to myocardial infarction in the city of São Paulo in Brazil, where 12,007 fatal events were observed from 1996 to 1998. The model was adjusted in a linear fashion for relative humidity and day-of-week, while nonparametric smoothing factors were used for seasonal trend and temperature. We found a significant association of daily temperature with deaths due to myocardial infarction $(\mathrm{P}<$ 0.001 ), with the lowest mortality being observed at temperatures between 21.6 and $22.6^{\circ} \mathrm{C}$. Relative humidity appeared to exert a protective effect. Sulfur dioxide concentrations correlated linearly with myocardial infarction deaths, increasing the number of fatal events by $3.4 \%$ (relative risk of $1.03 ; 95 \%$ confidence interval $=1.02$ 1.05 ) for each $10 \mu \mathrm{g} / \mathrm{m}^{3}$ increase. In conclusion, this study provides evidence of important associations between daily temperature and air pollution and mortality from myocardial infarction in a subtropical region, even after a comprehensive control for confounding factors.
Key words - Epidemiology

- Myocardial infarction

- Mortality

- Temperature

- Atmospheric pressure

- Air pollution

\section{Introduction}

An increase in mortality from heart disease in cold weather has been observed for more than half a century $(1,2)$. Analyses of seasonal fluctuations in myocardial infarction (MI) morbidity and mortality have shown a heterogeneous temporal distribution, with a peak in winter and a nadir in summer $(3,4)$.
This pattern is consistent across many regions of the world (5-8). Studies on meteorological variables, mainly temperature, have demonstrated a relatively large effect on both hospitalization and death from coronary heart disease $(9,10)$. In addition, studies on air pollution have provided evidence that increases in atmospheric pollution, both episodic events of extremely high levels and 
variations within the usual concentration range, are independently associated with an elevation of death by MI (11-13).

These findings have motivated investigators to study the biological mechanisms involved. Acute exposure to cold can increase blood pressure, sympathetic nervous activity, and platelet aggregation in humans (1416). Experimental and clinical data have shown that pollution levels are associated with changes in blood viscosity, heart rate variability, ischemic threshold, and occurrence of life-threatening arrhythmias (1719). Although several studies have been published about the association of environmental variables with death from MI $(20,21)$, only a few have used a comprehensive model that could clarify the independent contribution by the seasonal, meteorological, and air pollution conditions to an excess of coronary mortality. Also, only a small number of investigations of MI mortality have analyzed these associations using more precise and flexible statistical instruments $(13,22)$. The city of São Paulo is located on the Tropic of Capricorn, $46^{\circ}$ longitude, at $800 \mathrm{~m}$ altitude. As the city with the third largest population in the world, it offers a unique opportunity for an ecological study exploring the role of the environment in coronary mortality in a much different context of climate and mix of pollution sources compared with North America and Europe.

This kind of research is an important key for the understanding of the influence of the environment on coronary heart disease and may open new opportunities for preventive and therapeutic interventions. The objective of the present study was to examine the independent associations of seasonal, meteorological, and pollution variables with daily counts of death attributed to MI in the city of São Paulo, Brazil.

\section{Material and Methods}

Complete data from death certificates list- ing MI as a primary cause for the period of July 1996 to June 1998 were provided by the São Paulo Municipal Government Obituary Registry (Programa de Aprimoramento de Informações de Mortalidade), which is responsible for processing and revising for coherence all death certificates for persons who live within the metropolitan area. During this period, the population of São Paulo was 9,870,623 inhabitants, on average, as estimated by the State Statistics Department (Fundação Sistema Estadual de Análise de Dados). MI deaths were coded as I.21, that means acute MI, according to the International Classification of Diseases, tenth revision, considering all residents of São Paulo who died of nonviolent causes. A single code number was chosen instead of broader categories in order to obtain a more homogeneous sample with the purpose of exploring possible mechanisms of acute coronary heart disease. Daily mean concentrations of sulfur dioxide $\left(\mu \mathrm{g} / \mathrm{m}^{3}\right)$, measured by coulometry, carbon monoxide (ppm), measured by nondispersive infrared, and inhalable particulate matter less than $10 \mu \mathrm{m}$ in diameter $(\mu \mathrm{g} /$ $\mathrm{m}^{3}$ ), measured with a beta gauge, were provided by the State Environmental Agency (Companhia Estadual de Tecnologia em Saneamento Básico). The mean value of available measurements of pollutants at 13 monitoring stations distributed throughout the urban area was calculated for each day.

The daily measurements of mean atmospheric temperature $\left({ }^{\circ} \mathrm{C}\right)$, relative humidity $(\%)$, and pressure (mbar) obtained at a single location were provided by the Astronomy and Geophysics Institute of the University of São Paulo.

\section{Statistical analysis}

A table with Pearson correlation coefficients between daily deaths, weather variables, and pollutant concentration was generated. Multiple Poisson regression in a generalized additive model was adopted to study 
the associations between daily MI mortality, weather variables, and air pollution, controlling for seasonal trends, day-of-week, public holidays, and influenza incidence. By generating models using different spans of previous moving averages of air pollution (from the current day to a 7-day average) and weather variables (from the current day to a 2-day average), it was possible to compare the models obtained to achieve the best fitting, as described elsewhere (23). A robust regression design, which assigns a lower weight to outliers, was used to reduce the effect of any extreme observations on the regression results (24). This type of analysis was used to model the small expected effect of environmental factors, especially pollution, to control for the occurrence of days with atypical measures, secondary to holidays and influenza epidemics. A loess smooth function was included in the model to control for non-linearity in the dependence of mortality on seasonal trend and temperature. Loess estimates a smoothing function by fitting a weighted regression within a moving window, and the weights are close to one in the central third of the window, declining rapidly to zero outside that range, allowing a more flexible control of the variables in a given model. For seasonal variation, we used a window of 182 days that represented the seasonal pattern and for temperature a window of $50 \%$ of the data (13).

A second model including 10 categories (deciles) for daily temperature, instead of a loess-smoothing factor, was constructed to better display this variable graphically. A similar procedure was followed for quintiles of relative humidity and sulfur dioxide. Attributable deaths were calculated for each relevant factor as a percentage of total mortality (25).

\section{Results}

Included in the study were 12,007 fatal events secondary to MI, with a mean patient age of 67.8 years $(\mathrm{SD}=13.6)$ ranging from 35 to 109 years, and $6976(58.1 \%)$ men.

The distribution of the variables included in the analysis is shown in Table 1. The mean daily count of deaths due to all nonviolent causes was $129.8(\mathrm{SD}=19.5)$, the count due to cardiovascular diseases was 38.1 ( $\mathrm{SD}=$ 8.42), and the count to MI was 16.4 (SD = 5.0). The Pearson correlation (Table 2) revealed significant relationships between daily deaths secondary to MI, weather, and air pollution.

\section{Seasonality}

Associations between long- and shortterm seasonalities and MI mortality, respec-

Table 1. Distribution of deaths by diagnoses, weather and air pollution variables studied.

\begin{tabular}{lrccr}
\hline Variable & Mean & Maximum & Minimum & SD \\
\hline Mortality (deaths/day) & & & & \\
Non-violent deaths (ICD A00 to R99) & 129.8 & 203 & 82 & 19.5 \\
Cardiovascular deaths (ICD I00 to I52) & 38.1 & 70 & 14 & 8.4 \\
Myocardial infarction deaths (ICD I21) & 16.4 & 37 & 4 & 5.0 \\
Mean temperature $\left({ }^{\circ} \mathrm{C}\right)$ & 19.3 & 28.3 & 8.8 & 3.6 \\
Relative humidity $(\%)$ & 81.3 & 97 & 53 & 7.8 \\
Atmospheric pressure (mbar) & 925.4 & 935 & 917 & 3.7 \\
Sulfur dioxide $\left(\mu \mathrm{g} / \mathrm{m}^{3}\right)$ & 18.9 & 75.2 & 3.1 & 10.9 \\
Particulate matter $\left(\mu \mathrm{g} / \mathrm{m}^{3}\right)$ & 58.2 & 186 & 23 & 25.8 \\
Carbon monoxide $(\mathrm{ppm})$ & 3.7 & 11.8 & 1.0 & 1.6 \\
\hline
\end{tabular}

Data are reported as deaths per day unless otherwise stated. ICD = International Classification of Diseases; SD = standard deviation.

Table 2. Pearson correlation coefficients for the main variables studied.

\begin{tabular}{lcccccc}
\hline & Temperature & Humidity & AP & $\mathrm{CO}$ & $\mathrm{PM}$ & $\mathrm{SO}_{2}$ \\
\hline Temperature & 1 & & & & & \\
Humidity & $-0.28^{* * *}$ & 1 & & & & \\
$\mathrm{AP}$ & $-0.66^{* * *}$ & $0.11^{* *}$ & 1 & & & \\
$\mathrm{CO}$ & -0.01 & $-0.45^{* * *}$ & -0.03 & 1 & & \\
$\mathrm{PM}$ & $-0.12^{* *}$ & $-0.53^{* * *}$ & $0.22^{* *}$ & $0.73^{* * *}$ & 1 & \\
$\mathrm{SO}_{2}$ & $-0.20^{* * *}$ & $-0.37^{* * *}$ & $0.19^{* *}$ & $0.51^{* * *}$ & $0.72^{* * *}$ & 1 \\
$\mathrm{MI}$ & $-0.28^{* *}$ & $-0.09^{*}$ & $0.23^{* *}$ & $0.14^{* * *}$ & $0.17^{* * *}$ & $0.11^{* *}$ \\
\hline
\end{tabular}

$\mathrm{AP}=$ atmospheric pressure; $\mathrm{CO}=$ carbon monoxide; $\mathrm{PM}=$ particulate matter; $\mathrm{SO}_{2}=$ sulfur dioxide; $\mathrm{MI}=$ daily myocardial infarction deaths.

${ }^{*} P<0.05,{ }^{*} P<0.01,{ }^{*} * P<0.001$. 
Table 3. Regression estimates of daily mortality from myocardial infarction.

\begin{tabular}{lcc}
\hline Variable & $\begin{array}{c}\text { Estimated } \\
\text { coefficient }\end{array}$ & $\begin{array}{c}\text { Estimated } \\
\text { standard error }\end{array}$ \\
\hline Loess for seasonal trend & 0.992 & $0.325^{* *}$ \\
Day-of-week indicators & & \\
Monday & 0.086 & $0.036^{*}$ \\
Tuesday & -0.003 & 0.037 \\
Wednesday & 0.042 & 0.036 \\
Thursday & 0.003 & 0.037 \\
Friday & 0.072 & $0.036^{*}$ \\
Saturday & 0.030 & 0.037 \\
Environmental variables & & \\
Loess for temperature $\left({ }^{\circ} \mathrm{C}\right)$ & -1.586 & $0.347^{* * *}$ \\
Relative humidity $(\%)$ & -0.004 & $0.002^{* *}$ \\
Atmospheric pressure $(\mathrm{mbar})$ & 0.005 & 0.003 \\
Sulfur dioxide $\left(\mu \mathrm{g} / \mathrm{m}^{3} \times 100\right)$ & 0.36 & $0.18^{*}$ \\
Particulate matter $\left(\mu \mathrm{g} / \mathrm{m}^{3} \times 100\right)$ & 0.04 & 1.27 \\
Carbon monoxide $(\mathrm{ppm} \times 100)$ & 0.97 & \\
\hline
\end{tabular}

${ }^{*} \mathrm{P}<0.05,{ }^{*} \mathrm{P}<0.01,{ }^{*} * \mathrm{P}<0.001$

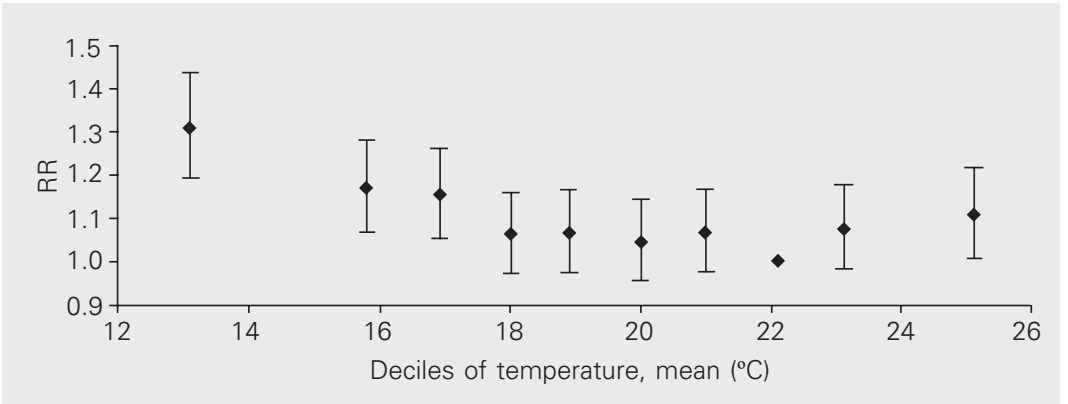

Figure 1. Relative risk (RR) of death (95\% confidence interval) from myocardial infarction by deciles of temperature, adjusted to seasonal trend, weather and pollution variables in São Paulo, 1996-1998. The total number of deaths from myocardial infarction was 12,007.

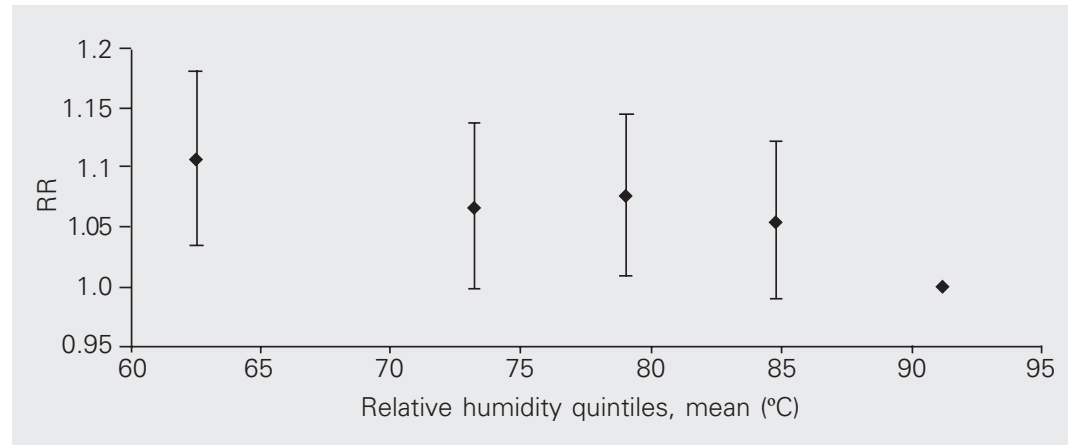

Figure 2. Relative risk (RR) of death ( $95 \%$ confidence interval) from myocardial infarction by quintiles of humidity, adjusted to seasonal trend, weather and pollution variables in São Paulo, 1996-1998. The total number of deaths from myocardial infarction was 12,007. tively, time trend and day-of-week variation, are presented in Table 3. When compared to Sundays, Mondays exhibited an increased mortality with a relative risk of $1.09(95 \%$ confidence interval, CI, 1.02-1.17).

\section{Weather effects}

The multiple regression model revealed a strong and robust association between daily MI mortality and mean temperature ( 2 days average). Figure 1 displays the association of MI mortality and deciles of temperature. This relationship is U-shaped $(\mathrm{P}<0.001)$, with a clear deleterious effect observed as temperature decreased from about $22^{\circ} \mathrm{C}$. A lesser effect of hot temperatures was seen with an increase in the relative risk of dying to 1.11 (95\% CI: $1.06-1.16)$ as temperature increased from $21.6-22.6$ to $23.8-27.3^{\circ} \mathrm{C}$. Temperature variation was associated with an excess of 1420 deaths $(11.8 \%$ of total MI deaths) during the study period.

Low humidity (2 days average) was a significant and independent variable associated with MI mortality with a relative risk of 1.11 (95\% CI: 1.03-1.18) when comparing the lowest and highest quintile of relative humidity (Figure 2). With the methodology used, we could not detect a significant and independent effect of atmospheric pressure on MI mortality.

\section{Air pollution effects}

Sulfur dioxide levels (4 days average) were significantly associated with mortality from MI both individually and when added to the other pollutants considered (Table 3), with no evidence of a safe threshold (Figure 3 ). The estimated effect of a $10 \mu \mathrm{g} / \mathrm{m}^{3}$ elevation in sulfur dioxide levels was a corresponding increase of $3.4 \%$ (relative risk of 1.03; 95\% CI: 1.02-1.05) in MI mortality. Carbon monoxide and inhalable particulate matter did not have significant effects on mortality either individually or when included 
with sulfur dioxide in the final model. The regression coefficients and standard errors (in parentheses) for each pollutant, included individually and with other pollutants, respectively, were as follows: sulfur dioxide $\left(\mu \mathrm{g} / \mathrm{m}^{3} \mathrm{x} 100\right), 0.34(0.15)$ and $0.36(0.18)(\mathrm{P}$ $<0.05)$; particulate matter $\left(\mu \mathrm{g} / \mathrm{m}^{3} \mathrm{x} 100\right), 0.1$ $(0.1)$ and 0.04 (0.08), nonsignificant, and carbon monoxide (ppm x 100), 1.42 (1.01) and 0.97 (1.27), nonsignificant.

\section{Discussion}

A growing body of evidence shows that MI is not a random event but, on the contrary is associated with several known triggering factors, including environmental variables (26). The present study confirms the independent association of both short- and longterm seasonality on MI mortality. These results give support to the stress-related return to work on Mondays as a possible trigger for fatal MI (3). The increase in MI mortality in winter even after controlling for meteorological fluctuations is intriguing and is not fully understood, although some investigators attribute this winter effect to the difference in the photoperiod (number of sunlight hours) between winter and summer (6). It is very interesting that the seasonal variation in MI morbidity in the second national registry of MI was equivalent in colder and warmer regions of the United States of America (4). A second study found that the seasonal variation in coronary mortality in Kuwait and Scotland is very similar (6). These studies suggest that an acclimatization of the population to the local climate occurs and that MI deaths peak in winter not only because of absolute low temperature but possibly secondary to a decrease relative to the average annual temperature.

Given the increase in blood pressure and sympathetic nervous output with cold temperatures, Green et al. (27) proposed the holding of clinical trials involving the adjustment of antihypertensive treatment for each season. The evident influence of temperature on MI mortality may be explained by multiple physiologic functions that are modified by environmental temperature. Cold exposure increases blood pressure, sympathetic nervous output, and platelet aggregation $(15,16)$. In addition, acute-phase factors, reported as prognostic elements in unstable angina, such as C-reactive protein, fibrinogen, and factor VII activity, are all higher in winter $(28,29)$.

On the other hand, high temperatures have also been found to induce profound physiologic changes such as an increase in blood viscosity and cardiac output leading to dehydration, hypotension, and even endothelial cell damage (30). A deleterious association of dry days with MI mortality was also noted by other investigators (13), possibly due to dehydration and consequent elevation of blood viscosity. The sympathetic system probably plays a major role in defining seasonal rhythms of acute MI. This view is supported by the study of Sayer et al. (31) that showed the absence of seasonal variation in MI patients taking beta-blockers and in individuals with diabetes, possibly due to a subjacent autonomic dysfunction.

In the present study, we demonstrated a strong association between daily temperature and MI mortality in São Paulo, Brazil. This association is non-monotonic, with a typical U-shape. The temperature at which the lowest mortality occurred in our study

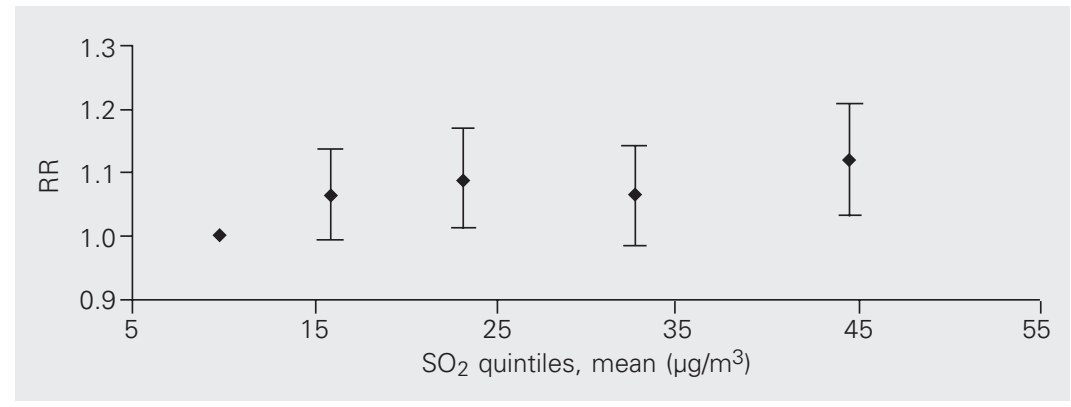

Figure 3. Relative risk (RR) of death ( $95 \%$ confidence interval) from myocardial infarction by quintiles of sulfur dioxide $\left(\mathrm{SO}_{2}\right)$, adjusted to seasonal trend, weather and pollution variables in São Paulo, 1996-1998. The total number of deaths from myocardial infarction was 12,007 . 
was around $22^{\circ} \mathrm{C}$. In other areas of the globe, the most favorable temperature varies widely, from $26-29^{\circ} \mathrm{C}$ in Taiwan (10) to $16^{\circ} \mathrm{C}$ in the Netherlands (32). Such variation may be explained by differences in housing conditions and by a process of acclimatization to the local climate. In fact, São Paulo, with a temperate climate, exhibits a much smaller range of temperatures than London and most cities in the United States of America. Nonetheless, the summer to winter mortality ratios were comparable to those reported for these cities. This can be explained by a steeper relationship between temperature and MI mortality in poor countries, like Brazil and Greece, with less house heating and weather protective garments (20).

Thus, it is important to emphasize the value of thermal comfort, with heating and insulation in winter and air-conditioning in summer, as well as outdoor weather protection for disease prevention, as demonstrated in the literature $(22,30)$. Although particulate matter less than 10 in diameter and total suspended particles were associated with excess MI mortality in several studies $(12,13)$, we only found an independent association with sulfur dioxide levels, which are very low in São Paulo. Sulfur dioxide is best known for its irritant effects on the respiratory system, but these effects do not seem to explain the excess mortality seen here. One possibility is that sulfur dioxide acts as a marker of other constituents produced in fossil fuel burning, like $\mathrm{SO}_{4}$ and fine particles (33), and for this reason could be associated with MI mortality (13).

\section{Limitations}

A limitation of the present study was that we relied on central station monitoring for meteorological factors and the mean of 13 monitoring stations for pollution levels, instead of measurements of personal exposure to environmental variables, a fact that could weaken the associations and introduce errors in the analysis of variance. However, considering the population as a whole, we can be confident that the relationships verified here are meaningful. Errors estimating individual exposure would minimize the magnitude of the observed effect of the ambient variables, tending to produce falsenegative results, so that the effects observed here were probably underestimated. The possible role of influenza as a contributor to winter peak death rates was not considered due to the lack of data on the incidence of viral respiratory disease. A second question is the quality of the data used in the present analysis. A quality study gives support to the reliability of the death certificate in coronary heart disease in the city of São Paulo, with a sensitivity and specificity similar to that of developed countries (34). It is not possible to prove a direct causality between environmental variables and MI mortality based only on observational studies; nevertheless, data available in the literature and in the present study point in this direction. Additional experimental and clinical research is necessary to ultimately confirm the existence of a direct effect and to better characterize the biological mechanisms involved.

\section{References}

1. Justin MN (1923). The effect of weather on health as shown by a study of the mortality statistics of New York city for the years 18831888. Doctoral thesis, Yale University, New Haven, CT, USA.

2. Chiaverini R \& Rey C (1947). Ensaio acerca das possíveis influências meteorológicas sobre a mortalidade cardiovascular. Revista Brasileira de Medicina, 4: 673-680.

3. Spielberg C, Falkenhahn D, Willich SN, Wegscheider K \& Heinz V
(1996). Circadian, day-of-week and seasonal variability in myocardial infarction: Comparison between working and retired patients. American Heart Journal, 132: 579-585.

4. Spencer FA, Goldberg RJ, Becker RC \& Gore JM (1998). Seasonal distribution of acute myocardial infarction in the second national registry of myocardial infarction. Journal of the American College of Cardiology, 31: 1226-1233. 
5. Marshall RJ, Scragg R \& Bourke P (1988). An analysis of the seasonal variation of coronary heart disease and respiratory disease mortality in New Zealand. International Journal of Epidemiology, 17: 325-331.

6. Douglas AS, Al-Sayer H, Rawles JM \& Allan TM (1991). Seasonality of disease in Kuwait. Lancet, 337: 1393-1397.

7. Seto TB, Mittleman MA, Davis RB, Taira DA \& Kawachi I (1998). Seasonal variations in coronary artery disease mortality in Hawaii: observational study. British Medical Journal, 316: 1946-1947.

8. Sheth T, Nair C, Muller J \& Yusuf S (1999). Increased winter mortality from acute myocardial infarction and stroke: the effect of age. Journal of the American College of Cardiology, 33: 1916-1919.

9. Marchant B, Ranjadayalan K, Stevenson R, Wilkinson P \& Timmis $A D$ (1993). Circadian and seasonal factors in the pathogenesis of acute myocardial infarction: the influence of environmental temperature. British Heart Journal, 69: 385-387.

10. Pan WH, Li LA \& Tsai MJ (1995). Temperature extremes and mortality from coronary heart disease and cerebral infarction in elderly Chinese. Lancet, 345: 353-355.

11. Logan WPD (1953). Mortality in the London fog incident, 1952. Lancet, 1: 336-338.

12. Schwartz J (1994). What are people dying of on high air pollution days? Environmental Research, 64: 26-35.

13. Rossi G, Vigotti MA, Zanobetti A, Repetto F, Gianelle V \& Schwartz $J$ (1999). Air pollution and cause-specific mortality in Milan, Italy, 1980-1989. Archives of Environmental Health, 54: 158-164.

14. Mudge GH, Grosman W, Mills RM, Lesch M \& Branwald E (1976). Reflex increase in coronary vascular resistance in patients with ischaemic heart disease. New England Journal of Medicine, 295: 1333-1337.

15. Keatinge WR, Coleshaw SRK, Cotter F, Mattock M, Murphy M \& Chelliak R (1984). Increases in platelet and red cell count, blood viscosity and arterial pressure during mild surface cooling: factors in mortality from coronary and cerebral thrombosis in winter. British Medical Journal, 289: 1405-1408.

16. Woodhouse PR, Khaw KT \& Plummer M (1993). Seasonal variation of blood pressure and its relationship to ambient temperature in an elderly population. Journal of Hypertension, 11: 1267-1274.

17. Allred EN, Bleecker ER, Chaitman BR, Dahms TE, Gottlieb SO, Hackney JD, Pagano M, Selvester RH, Walden SM \& Warren J (1989). Short term effects of carbon monoxide exposure on exercise performance of subjects with coronary artery disease. New England Journal of Medicine, 321: 1426-1432.

18. Peters A, Doring A, Wichimann HE \& Koenig W (1997). Increased plasma viscosity during an air pollution episode: a link to mortality? Lancet, 349: 1582-1587.

19. Peters A, Liu E, Verrier PL et al. (2000). Air pollution and incidence of cardiac arrhythmias. Epidemiology, 11: 2-4.

20. The Eurowinter Group (1997). Cold experience and winter mortality from ischaemic heart disease, cerebrovascular disease, respiratory disease, and all causes in warm and cold regions of Europe. Lancet, 349: 1341-1346.

21. Ballester F, Corella D, Pérez-Hoyos S, Sáez M \& Hérvas A (1997). Mortality as a function of temperature. A study in Valencia, Spain, 1991-93. International Journal of Epidemiology, 26: 551-561.

22. Danet S, Richard F, Montaye M, Beauchant S, Lemaire B, Graux C, Cottel D, Marecaux N \& Amouyel P (1999). Unhealthy effects of atmospheric temperature and pressure on the occurrence of myocardial infarction and coronary deaths. Circulation, 100: E1-E7.

23. Cleveland WS \& Devlin SJ (1988). Robust locally weighted regression and smoothing scatterplots. Journal of the American Statistical Association, 74: 829-836.

24. Hampel FR, Ronchetti EM, Rousseeuw PJ \& Stahel WA (1986). Robust Statistic: The Approach Based on Influence Functions. John Wiley, New York.

25. Ostro B, Sanchez J, Aranda C \& Eskeland G (1996). Air pollution and mortality: results from a study of Santiago, Chile. Journal of Exposure Analysis and Environmental Epidemiology, 6: 97-114.

26. Muller JE, Abela GS, Nesto RW \& Tofler GH (1994). Triggers, acute risk factors and vulnerable plaques: the lexicon of a new frontier. Journal of the American College of Cardiology, 23: 809-813.

27. Green MS, Harari G \& Kristal-Bone E (1994). Excess winter mortality from ischaemic heart disease and stroke during colder and warmer years in Israel. An evaluation and review of the role of environmental temperature. European Journal of Public Health, 4: 3-11.

28. Woodhouse PR, Khaw KT, Plummer M, Foley A \& Meade TW (1994). Seasonal variations of plasma fibrinogen and factor VII activity in the elderly: winter infections and death from cardiovascular disease. Lancet, 343: 435-439.

29. Thompson SG, Kienast J, Pylse SDM, Haverkate F \& Vandeloo JCW (1995). Hemostatic factors and the risk of myocardial infarction or sudden death in patients with angina pectoris. New England Journal of Medicine, 332: 635-641.

30. Rogot E, Sorlie PD \& Backlund E (1992). Air conditioning and mortality in hot weather. American Journal of Epidemiology, 136: 106-116.

31. Sayer JW, Wilkinson P, Ranjadayalan K, Ray S, Marchant B \& Timmis AD (1997). Attenuation or absence of circadian and seasonal rhythms of acute myocardial infarction. Heart, 77: 325-329.

32. Kunst AE, Looman CWN \& MacKenbach JP (1993). Outdoor air temperature and mortality in the Netherlands: a time-series analysis. American Journal of Epidemiology, 13: 331-341.

33. Schwartz J, Dockery DW, Neas CM, Wypij D, Ware JH, Spengler JD, Koutrakis P, Speizer FE \& Ferris Jr BG (1994). Acute effects of summer air pollution on respiratory symptom reporting in children. American Journal of Respiratory and Critical Care Medicine, 150: 1234-1242.

34. Laurenti R, Gotlieb SL, Souza JM, Fonseca LA \& Mello-Jorge MH (1981). Mortality characteristics from ischemic heart disease in adults, 15 to 74 years old, in the city of São Paulo. Arquivos Brasileiros de Cardiologia, 36: 85-89. 